\title{
Uso da tecnologia na educação, da história à realidade atual
}

\author{
Demerval Guilarducci Bruzzi *
}

\begin{abstract}
Resumo
Fruto de minha pesquisa de doutorado, o presente artigo tem como principal intenção apresentar um percurso histórico contemplando a evolução da tecnologia disponível a educação desde os idos de 1850 até os dias atuais, apontando de forma clara e direta ao leitor o caminho evolutivo das tecnologias, bem como suas possíveis aplicações, deixando claro que a educação desde os primórdios até os dias atuais sempre teve contato com algum tipo de tecnologia, contrariando alguns teóricos que atribuem a salvação da educação na adoção de um processo tecnológico. Palavra chave: Tecnologia, educação, história.
\end{abstract}

Use of technology in education, history, current reality

\section{Abstract}

Result of my doctoral research, this article has the intention to present a historical journey contemplating the evolution on the technology available to education from 1850 to the present day, pointing clearly and directly, to the reader, the evolutionary path of technology and its possible applications, making it clear that education from the earliest times to the present day has always had contact with some kind of technology, contrary to some theorists who attributed the salvation of education in the adoption of a technological process.

Keyword: Technologic, Education, history.

\section{Introdução}

No Brasil falamos muito sobre o uso da tecnologia na educação, mas pouco ainda fazemos. É claro que temos diversos projetos de sucesso, mas nenhum até hoje apresentou capacidade de capilaridade e profundidade para sua difusão. Devido a minha pesquisa de doutorado na universidade Católica de Brasília (tecnologia como potencializadora da auto estima do aluno do ensino médio da escola pública no Brasil), vejo todos os dias aportar nas mais diversas redes sociais pseudoespecialistas com mil e uma dicas e teorias acerca de como a tecnologia seria a salvação da educação, mas

\footnotetext{
Ex-Diretor do Ministério da Educação. Graduado em Economia. Mestre em Gestão e Criação de Objetos de Aprendizagem, pela Universidade Carlos III/Madrid. Mestre em Educação, pela Universidade Católica de Brasília. Doutorando em educação, pela Universidade Católica de Brasília. E-mail: gbruzzi@terra.com.br
} 
de concreto, tais especialistas nada tem a oferecer a não ser um pequeno momento de autopromoção.

O Impacto das TIC, na educação é, na verdade, um aspecto particular de um fenômeno muito mais amplo, relacionado com o papel dessas tecnologias na atual sociedade da informação - SI , segundo Cool e Monero (2010), fazendo surgir novas modalidades de educação, formais ou informais, individuais ou coletivas, de natureza autodidata ou sob a tutela de instituições de ensino; em formato presencial, híbrido, ou totalmente mediado por tecnologias digitais, desenhando um novo cenário para a educação. Como destacam Palloff \& Pratt (2002), os objetivos, papéis, metodologias e recursos digitais estão sendo repensados à medida que máquinas, redes eletrônicas e tecnologias móveis invadem os espaços de aprendizagem tradicionais, fazendo emergir conceitos e práticas relacionadas a sistemas informatizados, ambientes hipermídia e comunidades virtuais de aprendizagem.

De acordo com César Coll (um dos principais coordenadores da reforma educacional espanhola), e Carles Monereo (Doutor em Psicologia na educação da Universidade Autônoma de Barcelona):

'Estamos assistindo há décadas ao surgimento de uma nova forma de organização política, econômica, social e cultural, identificada como sociedade da informação (SI), que comporta novas maneiras de trabalhar, comunicarse, de relacionar-se, de aprender, de pensar, e, em suma, de viver'.

'E as TIC em sua dupla condição de causa e efeito, têm sido determinantes nessa transformação.

Entre todas as tecnologias criadas pelos seres humanos, aquelas relacionadas com a capacidade de representar e transmitir a informação, ou seja, as tecnologias da informação e da comunicação revestem-se de especial importância, porque afetam o dia a dia de alunos e professores. Vivemos em uma época em que as tic vão além da base comum do conteúdo. (CÉSAR e COLL, 2011, p17)

Nessa perspectiva, podemos considerar que a utilização significativa e crítica de computadores e recursos digitais contribuem para a construção e apropriação de conhecimentos dos sujeitos, ao permitir que professores e alunos possam compreender melhor sua realidade para transformá-la (JONASSEN, 2007).

Mas quando surgiram as tecnologias na educação? Após algumas pesquisas como as realizadas na Libary University of Kansas pelos jornalistas Benjamin Innes e Charles Wilson em seu artigo "The Learning Machines" para o New York times edi- 
ção de 19 setembro de 2010, aponta alguns dados interessantes, pois quando falamos em Tecnologias da Informação e Comunicação - TIC na educação, logo pensamos em Tablets, Smartphones, netbooks etc. No entanto, a educação vive as voltas com as tecnologias desde 1650. Com aparatos como o Horn-Book (tratava-se de uma madeira com impressos), utilizado para alfabetização de crianças e textos religiosos (era uma forma na época colonial de ajudar as crianças a aprender a ler e escrever). Entre 1850 a 1870 tivemos outro aparato curioso: o Ferule (tratava-se de uma espécie de espeto de madeira mais grosso, que servia como apontador/indicador). Tanto o Ferule (figura 2), como o Horn-Book (figura 1), tinham dupla aplicação, serviam tanto para aprendizagem como para castigo físico imputado á alunos dispersos e/ou que não conseguiam aprender as lições. O que reforçava a ideia de uma educação punitiva (não muito distante dos dias atuais, se compararmos os modelos de avaliação atuais com as punições físicas citadas).

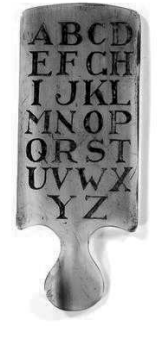

Fig. 1

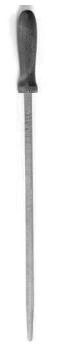

Fig. 2

Segundo Tardif (2015), tais tecnologias surgiram no plano da cultura material, ou seja, com a descoberta dos processos de impressão de imagens (gravura sobre madeira). Fato que acarretou uma expansão progressiva da cultura escrita até as camadas iletradas da sociedade, fazendo com que a cultura escolástica e dos clérigos deixassem de ser o centro cultural social.

Ainda segundo o autor, surgia uma nova ordem econômica (o capitalismo e a industrialização), assim, o surgimento do capitalismo industrial que vai do século XVIII até XIX aproximadamente, provocaria também um descentramento profundo de antigas práticas sociais, levando a educação a um novo patamar, que classifico como fabril.

As tecnologias foram na verdade, muito variadas e de certa forma deram origem aos devices atuais. Continuando nossa jornada passamos pela MAGIC LANTERN (figura 3) em 1870, percussora do nosso projetor de slides. Passamos depois pelo SCHOOL SLATE (figura 4) em 1890, seguido pelo CHALKBOARD (figura 5), 
ambos percussores do quadro negro/branco, também de 1890. Finalizamos a era das criações com o LÁPIS (figura 6) em 1900. Deste ponto em diante, considero apenas melhoramentos (aperfeiçoamento com base nas tecnologias já existentes), das invenções já descritas.

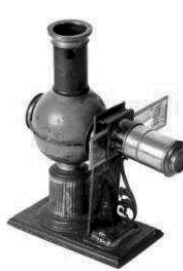

Fig.3

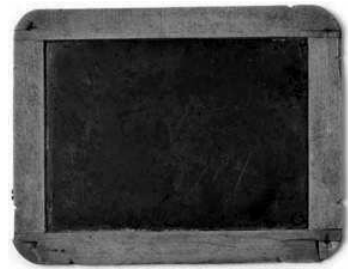

Fig. 4

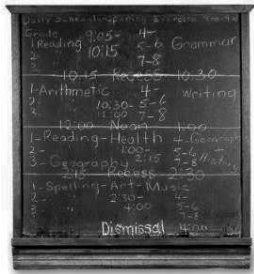

Fig. 5

Fig. 6

Continuando, tivemos em 1905 o ESTEREOSCOPE (modelo individual do projetor de slides - figura 7), o FILM PROJECTOR (figura 8) em 1925 como sendo o primeiro projetor de filmes (uma ideia melhorada do projetor de slides). Ainda em 1925 surge o RÁDIO (figura 9), seguido em 1930, pelo RETRO PROJETOR (inicialmente utilizado na área militar - figura 10). Desde o rádio considero (uma ideia pessoal), que a escola já estava na era da modernidade tecnológica, assim, em 1940 surge a CANETA ESFEROGRÁFICA e o MIMEOGRAFO (figura 11).

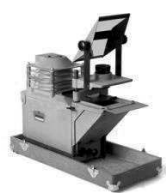

Fig.7

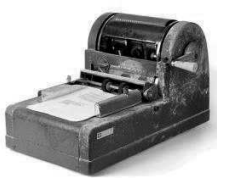

Fig. 8

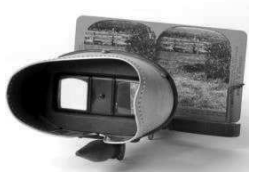

Fig. 9

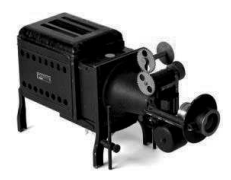

Fig. 10

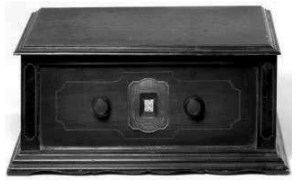

Fig. 11

Os VIDEOTAPES entram em cena 1951, acompanhados em 1957, de um instrumento pouco conhecido o ACELERADOR DE LEITURA (talvez o percussor da MÁQUINA DE APRENDIZAGEM de SKINER também de 1957). Em 1958 surge a TELEVISÃO EDUCATIVA, seguida pela FOTOCOPIADORA em 1959, que abre espaço para o nascimento do LIQUID PAPER em 1960.

De 1960 até os dias atuais uma enxurrada de tecnologia continua invadindo nossas escolas, dentre elas destaco: 


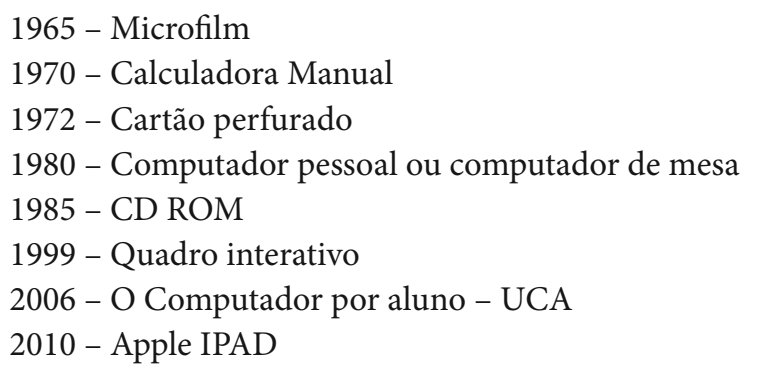

Como pode ser observado e ainda citando Cool e Moreno (2010), estamos assistindo já há algumas décadas, o surgimento de uma nova forma de organização econômica, social, política, cultural e educacional que atualmente chamamos de sociedade da informação (SI), que comporta novas maneiras de trabalhar, de comunicar-se, de relacionar-se, de aprender, de pensar, em suma de VIVER e CONVIVER.

Somente na atualidade demos crédito das transformações às tic, sendo que na verdade, as tic, há pelo menos três séculos têm assumido uma dupla condição de causa e efeito em nossas escolas, e se tornaram fatores determinantes para a transformação da atual sociedade.

Com seu papel notado e ampliado, as tics tem se tornado objeto de desejo e compulsão para alguns educadores. E pior, tais educadores atribuem a elas a saída para termos uma educação de qualidade e que atenda aos critérios da atual sociedade.

Tanto que Moraes (2011) coloca que, uma das afirmações mais comuns hoje em dia, é que o mundo está vivendo um processo de grandes transformações, profundas e aceleradas e que se modificam a cada instante.

É fato e ainda citando Moraes (2011), que não podemos negar que há uma nova demanda para um novo tipo de tecnologia, que, por sua vez, vem sendo gerada em decorrência do processo de maturação tecnológica e do desenvolvimento das telecomunicações.

Da mesma forma, não posso concordar 100\% com Pierre Lévy (1999), quando coloca que com a informatização surgiu um novo tipo de gestão social do conhecimento, na medida em que usamos um modelo digital que não é lido ou interpretado como um texto clássico, mas, explorado de forma criativa.

Pois, para que um aluno tenha condições de ler, interpretar ou mesmo explorar um texto, somente a tecnologia não basta. É necessário ter passado por um processo formativo, com apoio de profissionais dos mais diversos perfis, e que sejam realmente especialistas com visão diferenciada, uma visão transdiciplinar. Afinal se pensarmos 
apenas em tecnologia, há 360 anos convivemos com ela e nossas escolas não mudaram muito neste mesmo período.

Tanto uma escola, como um professor que queiram com as TIC provocar mudanças, necessitam de um novo perfil. Este novo perfil segundo Moraes (2010), implica mudanças na visão intelectual e social no papel do professor, pois ao trabalhar com as TIC reconhece-se as incertezas e necessidades de fundamentar-se não só nas disciplinas em que atuam, mas principalmente nos aspectos históricos locais, aceitando a inexistência de verdades absolutas e a presença de diferentes possíveis métodos e metodologias de trabalho com as tic, o que naturalmente transformará a forma de pensar, e sua compreensão social do mundo e da vida.

Não basta a tecnologia, é necessário uma formação adequada dos atores educacionais para que proporcionem as mudanças esperadas pela sociedade. Da mesma forma que, não basta á tecnologia presente em nossas escolas, é necessário proporcionar um norte, uma "tutoria" para que esta nova geração possa usar todo seu conhecimento tecnológico de forma a ampliar sua capacidade de ler, interpretar ou mesmo explorar os conteúdos educacionais. Somente assim, se cria um vinculo direto a necessidade atual do aluno, ou mesmo, a busca de soluções para problemas reais que emergem com o novo conhecimento adquirido.

Uma tecnologia educacional como o computador ou a internet, por meio do recurso de redes interativas, favorece novas formas de acesso à informação e à comunicação, e amplia as fontes de pesquisa em sala de aula, criando novas concepções dentro da realidade atual, abrindo espaço para a entrada de novos mecanismos e ferramentas que facilitem as ligações necessárias a fim de atender ao novo processo cognitivo do século XXI.

No entanto, é importante termos em mente a necessidade de uma formação adequada para nossos professores, afinal segundo Cysneiros (2000, p.2) "nem todos os aprendizes, sejam professores ou alunos, tem condições de descobrir espontaneamente usos interessantes de software". As pessoas aprendem diferentemente umas das outras, alguns podem aprender pela curiosidade, pelo manuseio, individualmente, outros necessitam de um suporte para obterem melhores resultados em sua aprendizagem.

Este novo cenário que para muitos é desconhecido, para nossos alunos é seu habitat natural. Assim, podemos também nos fazer valer da tecnologia para criação de uma nova forma de atuação, onde alunos e professores não tem lugar definido, ambos são agentes ativos dos processos de ensino e aprendizagem.

Segundo Nóvoa (1997), a troca de experiências entre os alunos e docentes solidifica os espaços de formação conjunta, onde cada individuo é chamado a desempenhar, simultaneamente, o papel de formador e de formando. 
Este novo olhar pode representar um novo momento epistemológico do sujeito. Onde, segundo Tardif (2014), seremos reconhecidos como sujeitos do conhecimento e verdadeiros atores sociais quando começarmos a reconhecer-nos uns aos outros como pessoas competentes, pares iguais que podem aprender uns com os outros, respeitando o conhecimento do professor em sua área de atuação de forma simultânea em que se reconhece o conhecimento do aluno com as novas tecnologias.

O saber fazer resulta da construção ou da articulação de um conhecimento que opera em rede, produto de uma espiral recursiva que articula diferentes saberes. Afinal como bem coloca Moraes (2010), vivemos um momento de mutação na relação sujeito objeto. Assim, quando as amarras do tradicionalismo pedagógico forem vencidas, abriremos espaço para a criação e construção de um novo modelo de educação.

Mas devemos estar atentos a fala de Bauman (2013) quando acertadamente coloca que nossa cultura baseada num insaciável apetite por novidade é a responsável por não termos uma verdadeira revolução cultural, uma vez que os poderes do atual sistema educacional estejam limitados, justamente pelo próprio sistema estar submetido ao jogo consumista, imputado à educação com o surgimento das TIC.

Neste ponto é importante colocar que em hipótese alguma sou contra a utilização das TIC em sala de aula, mas sim, de uma utilização sem possibilidade de replicabilidade e sem base cientifica de sua eficiência e eficácia no desenvolvimento da educação. O que não podemos aceitar é a máxima do mínimo aceitável, ou seja, aceitar que por nossas escolas passarem tantos anos de privação, passem a aceitar "qualquer" solução como sendo uma saída, afinal, sabe-se que anos de privação nos fazem crer que a servidão passa a ser percebida como uma liberdade de escolha.

Esta nova geração da internet, já entendeu que o segredo está na mobilidade e não no conteúdo (como ainda pregam alguns dos oportunistas da rede), pois o conteúdo pouco mudou. Neste período em que se desenvolveu a internet e demais tecnologias a única disciplina que teve seu conteúdo alterado foi à química (com a inclusão de quatro novos elementos) e assim mesmo, tal fato ocorreu já em 2016. Nossos conteúdos não mudaram, nem a necessidade real de se aprendê-los.

Pois quando oportunizamos aos nossos alunos um novo formato de conteúdo (sem este necessariamente estar atrelado à forma tradicional), abrimos espaço ao novo, ao diferente. Retomamos o processo de criação e motivação deste aluno. Processo este, já muito visto e debatido desde os escritos de Comenius, que foram replicados e aperfeiçoado por tantos outros grandes mestres como Juan Pozo, Frank Laubach, Alvaro Vieira Pinto, Paulo Freire, entre outros. Os processos de ensino e 
aprendizagem vêm e vão, em um espiral recursivo onde de acordo com Maturana (2001) faz com que a partir deste nosso viver cotidiano, escutemos alguém. No entanto, o que ouvimos é um acontecer interno a nós, e não o que o outro diz ou reproduz, embora o que ouvimos seja desencadeado pelo outro, a produção subjetiva de significado a fala é nossa.

Assim sendo, o que nos falta é criar condições de formações de base e continuada, para que nossos professores consigam trabalhar com as TIC mediando os processos de ensino e aprendizagem, buscando separar conteúdo de forma para que possamos atingir e desperta a maioria de nossos alunos, por meio de um processo individual dentro do coletivo, unidade na diversidade de uma sala de aula. Algo possível apenas por meio da tecnologia e com professores bem formados.

\section{Referências}

ALMEIDA, M. E. B.; PRADO, M. E. B. B. Criando situações de aprendizagem colaborativa. In: VALENTE, J. A.; ALMEIDA, M. E. B.; PRADO M. E. B. (Org.). Internet e formação de educadores a distância. São Paulo: Avercamp, 2003.

BRUZZI, D. Ação institucional de avaliação sobre a disseminação de tecnologia educacional no projeto UCA - Um computador por Aluno Brasil - UFC 2012.

DONSKIS, L. e BAUMAN Z. Cegueira Moral: A Perda da Sensibilidade na Modernidade Líquida. Editora ZAHAR - São Paulo, 2014.

COLL, C. O Construtivismo na sala de aula. Ática, São Paulo, 2011.

CYSNEIROS, P. G. Professores e máquinas: uma concepção de informática na educação. Disponível em: http://edutec.net/Textos/Alia/PROINFO/prf_txtie08.htm Acesso em 10/02/2010.

CYSNEIROS, P. G. Iniciação à informática na perspectiva do educador. Revista Brasileira de Informática na Educação (UFSC), n.7, p. 49-64, set. 2000.

CYSNEIROS, P. G. Novas tecnologias na sala de aula: melhoria do ensino ou inovação conservadora, Anais do Encontro Nacional de Didática e Prática de Ensino, 199-216. 
CYSNEIROS, P. G. Novas tecnologias na sala de aula: melhoria de ensino ou inovação conservadora? In: Endipe, IX, Águas de Lindóia/SP. Anais, II, 1998, p. 199-216.

ELBAZ, F -. Teacher thinking: A study of practical knowledge. London: Croom Helm. 1983.

ERTMER, P. Teacher pedagogical beliefs: the final frontier in our quest for technology integration? Educational Technology Research and Development. Vol. 53, n. 4, 2005. p. 25-39.

JONASSEN, D. H., Computadores, Ferramentas Cognitivas: Desenvolver o pensamento crítico nas escolas, Colecção Ciências da Educação Século XXI, Porto Editora, Porto, 2007.

KENSKI, V. M. Tecnologia e ensino presencial e a distância. Campinas, SP: Papirus, 2003

LEVY, P. Cibercultura. Rio de Janeiro: Ed. 34. 1999.

MATURANA. H. Cognição, Ciência e Vida Cotidiana. Editora UFMG - Belo Horizonte, 2001.

MORAES, M. C. e NAVAS, J. M. B. Complexidade e Transdiciplinaridade em Educação, Editora Wak, Rio de Janeiro, 2010.

MORAES, M. C. O paradigma educacional emergente. Campinas: Papirus, 2011.

NÓVOA, A. Formação de professores e profissão docente. In: NÓVOA, A. (Coord.). Os professores e sua formação. 3. ed. Lisboa: Dom Quixote, 1997. p. 9-33

PALLOFF, R. M.; PRATT, K. Construindo comunidades de aprendizagem no ciberespaço: estratégias eficientes para a sala de aula on-line. Tradução Vinícius Figueira. Porto Alegre: Artmed, 2002

TARDIF, M. Saberes docentes e formação profissional. 3. ed. Petrópolis: Vozes, 2002/2014.

Recebido em: 18 abril 2016.

Aceito em: 29 abril 2016. 